\title{
Using Room Temperature Phosphorescence of Gold(I) Complexes for PAHs Sensing
}

\author{
Marian Rosental ${ }^{1,2}$, Richard N. Coldman ${ }^{1}$, Artur J. Moro ${ }^{3}$, Inmaculada Angurell ${ }^{1,4}{ }^{\mathbb{D}}$, Rosa M. Gomila ${ }^{5}$, \\ Antonio Frontera ${ }^{6}$, João Carlos Lima ${ }^{3}(\mathbb{D})$ and Laura Rodríguez ${ }^{1,4, * \mathbb{C}}$
}

1 Department of Inorganic and Organic Chemistry, Inorganic Chemistry Section, Universitat de Barcelona, Martí i Franquès 1, 08028 Barcelona, Spain; Rosental@stud.uni-heidelberg.de (M.R.); richard.n.coldham@gmail.com (R.N.C.); inmaculada.angurell@qi.ub.es (I.A.)

2 Institute of Inorganic Chemistry, Heidelberg University, Im Neuenheimer Feld 270, 69120 Heidelberg, Germany

3 LAQV-REQUIMTE, Departamento de Química, Universidade Nova de Lisboa, 2829-516 Caparica, Portugal; artur.moro@gmail.com (A.J.M.); lima@fct.unl.pt (J.C.L.)

4 Institut de Nanociència i Nanotecnologia (IN2UB), Universitat de Barcelona, 08028 Barcelona, Spain

5 Serveis Científico Tècnics, Universitat de les Illes Balears, Crta de Valldemossa km 7.5, 07122 Baleares, Spain; rosa.gomila@uib.es

6 Departament de Química, Universitat de les Illes Balears, Crta de Valldemossa km 7.5, 07122 Baleares, Spain; toni.frontera@uib.es

* Correspondence: laura.rodriguez@qi.ub.es

check for updates

Citation: Rosental, M.; Coldman, R.N.; Moro, A.J.; Angurell, I.; Gomila, R.M.; Frontera, A.; Lima, J.C.;

Rodríguez, L. Using Room

Temperature Phosphorescence of Gold(I) Complexes for PAHs Sensing. Molecules 2021, 26, 2444. https:// doi.org/10.3390/molecules26092444

Academic Editor: Susana Ibáñez Maella

Received: 29 March 2021

Accepted: 18 April 2021

Published: 22 April 2021

Publisher's Note: MDPI stays neutral with regard to jurisdictional claims in published maps and institutional affiliations.

Copyright: (c) 2021 by the authors. Licensee MDPI, Basel, Switzerland. This article is an open access article distributed under the terms and conditions of the Creative Commons Attribution (CC BY) license (https:/ / creativecommons.org/licenses/by/ $4.0 /)$.

\begin{abstract}
The synthesis of two new phosphane-gold(I)-napthalimide complexes has been performed and characterized. The compounds present luminescent properties with denoted room temperature phosphorescence (RTP) induced by the proximity of the gold(I) heavy atom that favors intersystem crossing and triplet state population. The emissive properties of the compounds together with the planarity of their chromophore were used to investigate their potential as hosts in the molecular recognition of different polycyclic aromatic hydrocarbons (PAHs). Naphthalene, anthracene, phenanthrene, and pyrene were chosen to evaluate how the size and electronic properties can affect the host:guest interactions. Stronger affinity has been detected through emission titrations for the PAHs with extended aromaticity (anthracene and pyrene) and the results have been supported by DFT calculation studies.
\end{abstract}

Keywords: gold(I); polycyclic aromatic hydrocarbons (PAHs); molecular recognition; room temperature phosphorescence; DFT

\section{Introduction}

1,8-Naphthalimides (NI) represent a large family of compounds that are easily tunable and highly thermally and chemically stable. Their well-known photophysical properties makes them ideal candidates to be explored in different real-life applications such as the production of organic photochemical dyads and triads, energy storage, light conversion, gels, hybrid materials, optoelectronic devices, solar cells, sensors, biological applications, and bioimaging probes among others [1-9].

NI can be easily functionalized allowing not only the possibility to modulate their emission properties on a large scale [1] but also the design of ligands able to coordinate metal atoms giving rise to NI-metal complexes, though these have been less explored than purely organic NI-derivatives. They are also well known to establish $\pi-\pi$ intermolecular contacts giving rise to the formation of aggregates, affecting their resulting luminescence in connection with the aggregation induced emission (AIE) and aggregation caused quenching (ACQ) concept $[1,6,10,11]$. Although fluorescence emission is mainly observed in diluted NI-solution samples, phosphorescence may also be achieved in some cases, such as NIaggregates or when included within a macrocyclic host [12-14]. The heavy atom effect is 
another way to induce room temperature phosphorescence (RTP) and, to the best of our knowledge, there are very few examples in the literature in the coordination of NI to heavy metals to induce RTP emission and all are platinum derivatives [15-17].

In this way, gold(I) emerges as a new route to obtain RTP NI-complexes, since it is well known to enhance intersystem crossing and triplet state population [18-21]. Nevertheless, although there are few examples of gold(I)-NI complexes in the literature, they present fluorescence emission but not phosphorescence [4,22-26].

NI-fluorescence has been used in the molecular recognition of anions, cations and organic molecules [27-32]. Changes on the RTP emission band for sensing processes has not been explored in great detail and is a new subject for gold(I)-NI complexes. Hence, the present investigation focuses on the design and synthesis of new 1,8-naphthalimide based gold(I) complexes that display RTP and explores their use in molecular recognition processes. In particular, we are interested in sensing polycyclic aromatic hydrocarbons (PAHs) since they are well-known environmental contaminants with toxic, mutagenic, and carcinogenic properties $[33,34]$.. They can be found in different natural sources such as water and soil and are produced from fossil fuels, industrial manufacturing, residential heating, food preparation, etc. In particular, low molecular weight PAHs (2-3 rings) usually show a higher concentration in water than high molecular weight PAHs (4-6 rings) since they present a higher vapor pressure and solubility in water [34]. Their planar aromatic structure makes them ideal candidates to interact with the NI-core, inducing changes on the emission properties of the gold(I) complexes used as hosts in an easy and fast process. Most importantly, the high sensitivity of luminescence will allow the detection of very low quantities of PAHs.

\section{Results and Discussion.}

\subsection{Synthesis and Characterization}

The synthesis of the two new gold(I) complexes containing a naphthalimide chromophore was performed after previous derivatization of the napthalimide group with a terminal acetylene moiety with slight modifications of the procedure reported in the literature [35]. It is based on a three steps reaction where the 4-bromo-1,8-naphthalic anhydride gives the 6-bromo- $1 H$-benzo[de].isoquinoline-1,3(2H)-dione (P1) that will lead to the final $\mathbf{L}$ compound through a Sonogashira reaction (Scheme S1).

The deprotonation of the naphthalimide ligand $\mathbf{L}$ with potassium hydroxide followed by the addition of the stoichiometric amount of [AuCl(PTA)]. or [AuCl(DAPTA)]. (PTA = 1,3,5-Triaza-7-phosphaadamantane; DAPTA = 3,7-Diacetyl-1,3,7-triaza-5-phosphabicyclo [3.3.1].nonane) gold(I) sources yields the desired products $\mathbf{1}$ and $\mathbf{2}$ in moderate yield (ca. $50 \%$, Scheme 1).

The absence of the terminal alkynyl $\mathrm{C} \equiv \mathrm{C}-\mathrm{H}$ proton of $\mathbf{L}$ in the IR and NMR spectra of the complexes confirms the ligand bonds through its alkynyl motif (see Figures S1-S5). A ca. $0.3 \mathrm{ppm}$ upfield shift of naphthalimide signals and the appearance of the expected pattern of the PTA/DAPTA protons in the corresponding ${ }^{1} \mathrm{H}-\mathrm{NMR}$ spectra confirm the successful synthesis of the complexes. The ${ }^{31} \mathrm{P}-\mathrm{NMR}$ spectra indicate the presence of a main peak at ca. -49 and $-27 \mathrm{ppm}$ for 1 and 2 respectively in accordance with P-donor coordination to the metal center [36,37]. HRESI-MS spectrometry gives the final evidence of the correct formation of the compounds with the corresponding molecular $[\mathrm{M}+\mathrm{H}] \cdot{ }^{+}$peaks at $\mathrm{m} / \mathrm{z}$ 575.0922 and 647.1134 for 1 and 2, respectively. The presence of broad signals at ${ }^{1} \mathrm{H}-\mathrm{NMR}$ and additional peaks at ${ }^{31} \mathrm{P}-\mathrm{NMR}$ spectra suggest possible intermolecular aggregation assemblies, which was confirmed through different methodologies (see below). 


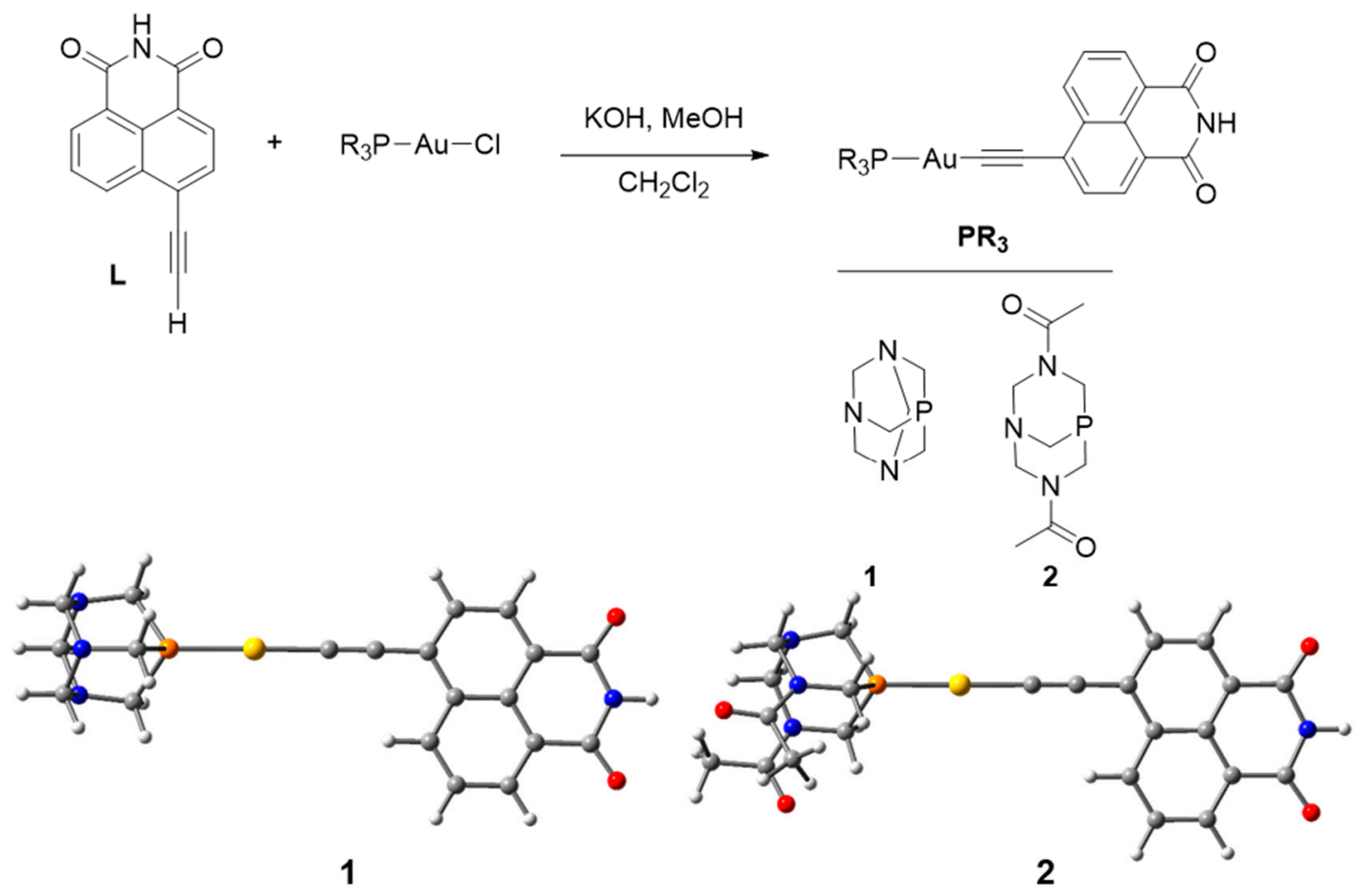

Scheme 1. Reaction for the syntheses of the phosphane-gold(I)-napthalimide complexes $\mathbf{1}$ and $\mathbf{2}$.

\subsection{Photophysical Characterization}

Absorption, emission and excitation spectra of $\mathbf{L}$ and complexes $\mathbf{1}$ and $\mathbf{2}$ were recorded in DMSO at $2 \times 10^{-5} \mathrm{M}$ and the results are summarized in Table 1 .

Table 1. Absorption and emission $\left(\lambda_{\text {exc }}=418 \mathrm{~nm}\right)$ spectral data of $\mathbf{L}, \mathbf{1}$ and $\mathbf{2}$ in DMSO.

\begin{tabular}{ccc}
\hline Compound & $\begin{array}{c}\left.\text { Absorption } \lambda_{\max } \mathbf{( n m}\right) \\
\left(\mathbf{1 0}^{-3} \boldsymbol{\varepsilon}\left(\mathbf{M}^{-\mathbf{1}} \mathbf{\mathbf { } m ^ { - 1 }}\right) \mathbf{)}\right.\end{array}$ & Emission $\lambda_{\text {max }} \mathbf{( n m )}$ \\
\hline $\mathbf{L}$ & $367(14.1), 349(15.9)$ & - \\
$\mathbf{1}$ & $420(10.5), 397(13.9), 370(9.8)$ & $456,621,676$ \\
$\mathbf{2}$ & $421(12.3), 396(15.9), 372(12.3)$ & $457,621,675$ \\
\hline
\end{tabular}

The absorption spectra of the compounds display a vibronically structured band with spacings of $1368 \mathrm{~cm}^{-1}$ corresponding to $\pi-\pi^{*}$ intraligand transition of the naphthalimide ligand $[9,22,24,38-41]$. This band is ca. $50 \mathrm{~nm}$ red-shifted upon coordination to the metal atom, as commonly observed for other chromophores coordinated to the $\mathrm{Au}(\mathrm{I})$ unit (Figure 1) [36,37]. The emission of 1 and 2 display two bands, one at ca. $455 \mathrm{~nm}$ due to the intraligand fluorescence emission of the naphthalimide group and another at longer wavelengths (ca. $620 \mathrm{~nm}$ ) attributed to the phosphorescence of the chromophore [12,22,23,39,41]. The phosphorescence assignment is evidenced by the quenching of the intensity of this emission band in the presence of oxygen (Figure S10) and can be achieved thanks to the presence of the gold(I) heavy atom that favors the intersystem crossing and population of the emissive triplet state [42]. The heavy atom effect on room temperature phosphorescence of gold(I) naphthalimide complexes is reported herein for the first time although it has previously been observed in platinum complexes, with the similar vibronically structured shape [39]. Previous luminescent studies with other gold(I)-napthalimide complexes contain $N$-substituted napthalimide chromophores and display pure fluorescence emission [22-26]. In our cases, the naphthalimide group does not present any substitution, being thus less bulky. Hence, the resulting higher planarity of the ligand in our systems may favor the approach between different molecules being the chromophore more affected 
by the presence of the heavy atom of the neighbor molecules, affecting the resulting phosphorescence emission. No significant emission of $\mathbf{L}$ was recorded in DMSO although it is emissive in $\mathrm{CH}_{2} \mathrm{Cl}_{2}$ (Figure S11).
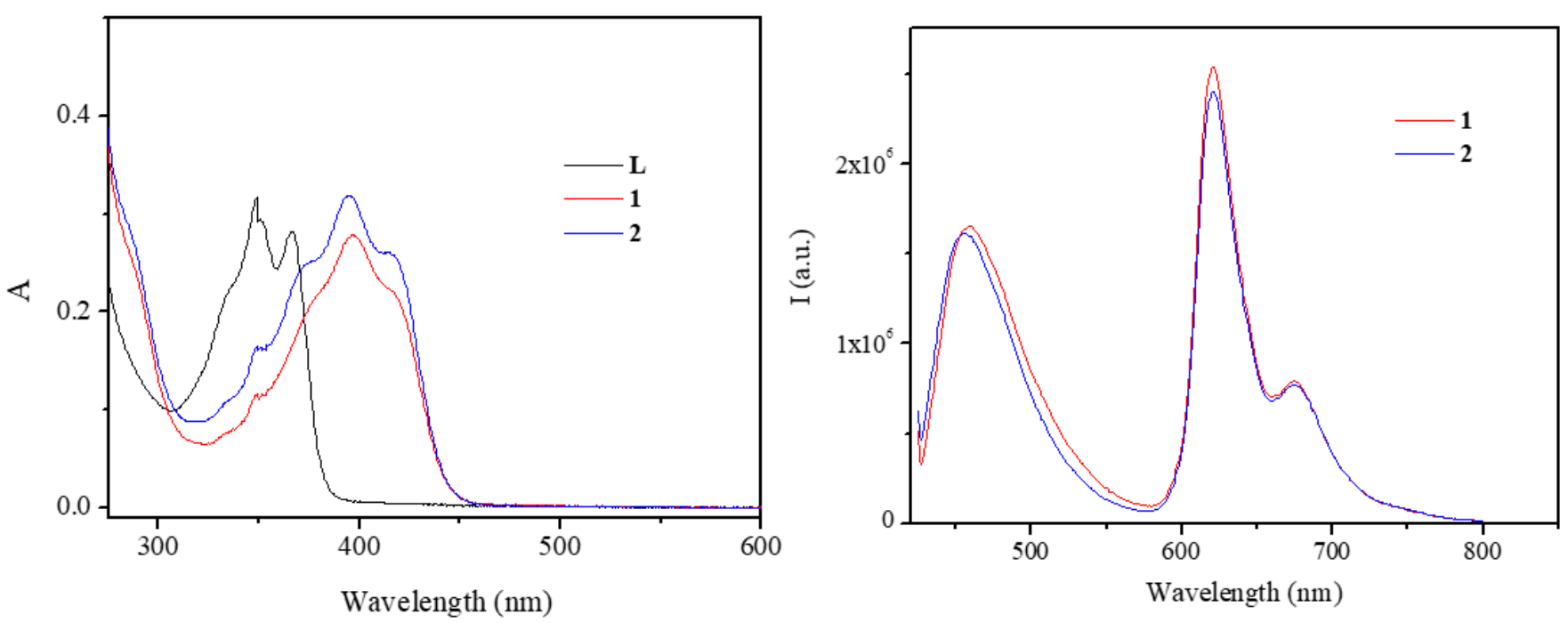

Figure 1. Absorption (left) and emission $\left(\lambda_{\text {exc }}=418 \mathrm{~nm}\right.$, right $)$ spectra of $\mathbf{L}$ and complexes $\mathbf{1}$ and 2 in DMSO.

The room temperature phosphorescence (RTP) of the gold(I) complexes may be observed thanks to the presence of the gold(I) atom in the proximity of the chromophore through intermolecular packing. This is in agreement with the corresponding ${ }^{1} \mathrm{H}-\mathrm{NMR}$ of freshly prepared samples of $\mathbf{1}$ and $\mathbf{2}$ (Figures 2 and S12) which display very low intensity of the aromatic protons, with lower integration values with respect to the rest of the protons of the molecules, the phosphane moieties, as usually happens in this type of gold(I) supramolecular assemblies. Thus this serves as direct evidence of the presence of these aggregation motif [43].

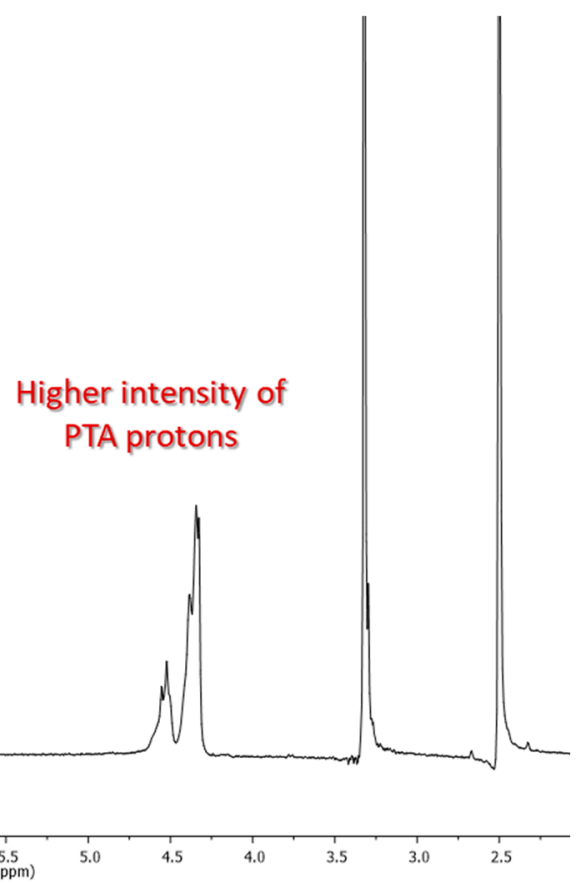

Figure 2. ${ }^{1} \mathrm{H}-\mathrm{NMR}$ spectrum of freshly dissolved solution of $\mathbf{1}$ in DMSO- $d_{6}$. 
In fact, intermolecular contacts are expected to happen even at lower concentrations than those used for ${ }^{1} \mathrm{H}-\mathrm{NMR}$ and have been verified to start at concentrations of ca. $2 \times 10^{-5} \mathrm{M}$ and $5 \times 10^{-5} \mathrm{M}$ (critical aggregation concentrations, c.a.c.) for $\mathbf{1}$ and $\mathbf{2}$, respectively, by recording emission spectra at increasing concentrations (Figures S13 and S14). The lower c.a.c. value of $\mathbf{1}$ is due to the well-known lower solubility of the PTA phosphane compared to DAPTA. Small well-organized aggregates have been also detected by optical microscopy with cross polarizers (Figure S15).

The molecular electrostatic potential (MEP) of compounds $\mathbf{1}$ and $\mathbf{2}$ have been computed through DFT, to investigate the most electron rich and poor regions of the molecule. The MEP plots are shown in Figure 3, indicating that the most nucleophilic region corresponds to the $O$-atoms of the naphthalimide unit and the most electrophilic one to the $H$-atoms of the phosphine ligands.
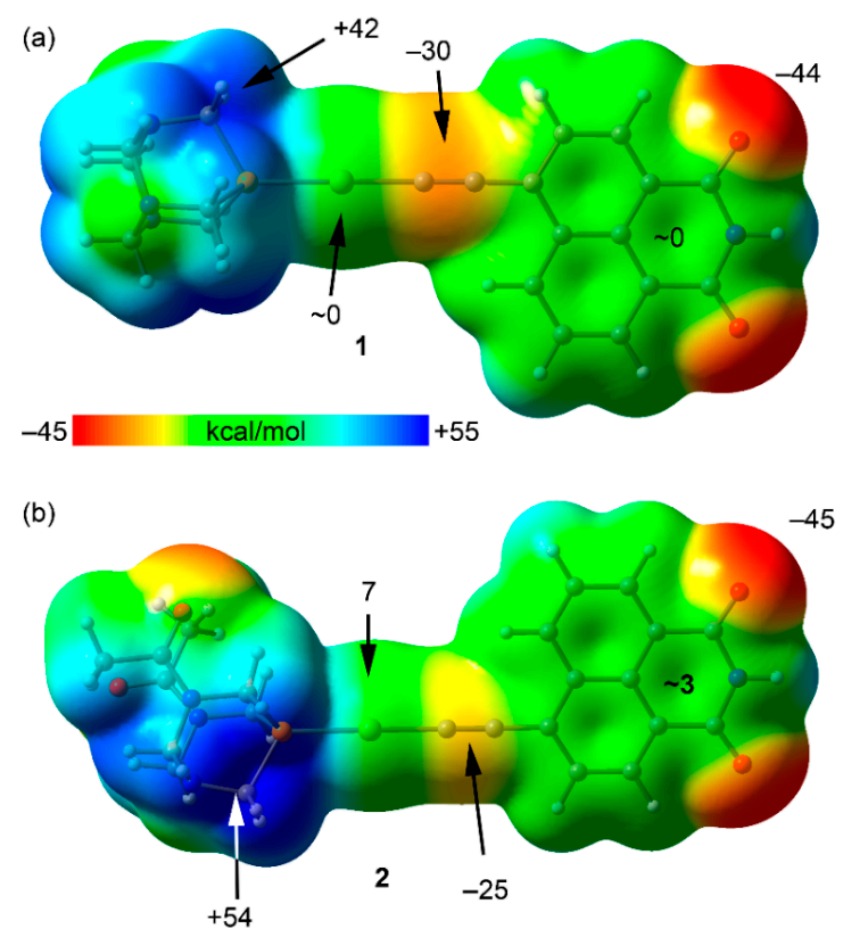

Figure 3. MEP surfaces (isovalue 0.001 a.u.) of compounds $\mathbf{1}$ (a) and $\mathbf{2}$ (b). The values at selected points of the surfaces are indicated in $\mathrm{kcal} / \mathrm{mol}$.

The MEP is also negative above and below the triple bond and slightly positive at the $\mathrm{Au}$ atom in case of compound 2. The MEP values are small over the naphthalimide unit.

The ability for self-assembly and aggregation of compounds $\mathbf{1}$ and $\mathbf{2}$ has been computed from the possible self-assembled dimers. The obtained geometries are given in Figure 4 and they adopt an antiparallel arrangement where the naphthalimide unit approaches the phosphane ligand in order to maximize the electrostatic attraction between the negative $\mathrm{O}$-atoms of naphthalimide and the positive $\mathrm{H}$-atoms of the Au-coordinated phosphine, in line with the MEP surface analysis. The dimerization energy is larger in compound $\mathbf{1}$, in agreement with the larger ability of $\mathbf{1}$ to form aggregates in DMSO. In the "on-top" representation of the assemblies, it can be observed that there is not $\pi$-overlap in compound $\mathbf{1}$ and, contrariwise, a small overlap between the $\pi$-systems of compound 2 is observed. 
(a)

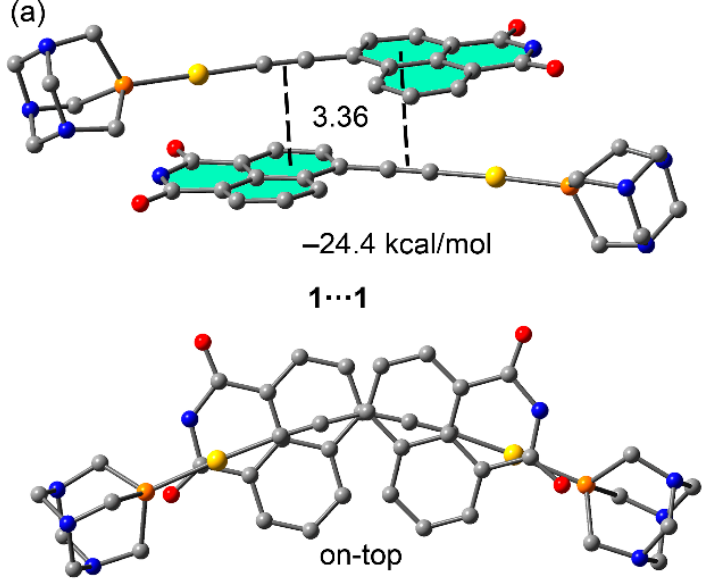

(b)

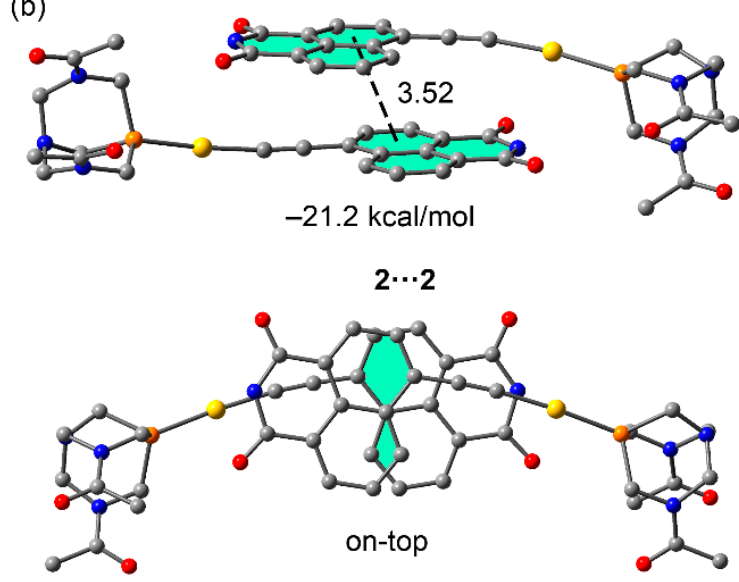

Figure 4. PB86-D3(COSMO)/def2-TZVP optimized geometries of the self-assembled dimers of $\mathbf{1}$ (a) and 2 (b). Distances in $\AA$.

\subsection{Molecular Recognition of Polycyclic Aromatic Hydrocarbons, PAHs}

The emissive properties of the gold(I) compounds together with the planarity of the organic chromophore encouraged us to use them as hosts for the molecular recognition of PAHs, being suitable for detection at very low concentrations. With this goal in mind, naphthalene, anthracene, phenanthrene, and pyrene, which differ by the number and position of aromatic rings with an effect on the corresponding size and shape were chosen as target PAHs. Absorption and emission titrations were performed and the changes on the spectroscopic properties of the hosts, $\mathbf{1}$ and 2, were followed upon addition of different amounts of the corresponding guest. No significant changes were recorded in any case in the absorption spectra of the host, besides the expected presence of increasing amounts of guest molecules. More interesting data were retrieved from emission titrations. In general trends we can observe the formation of 1:2 host:guest adducts and stronger interactions between the host molecules and PAHs with extended aromaticity present: antracene $\geq$ pyrene $>$ phenanthrene $>$ naphthalene. Additionally, the resulting adducts with compound 2 are expected to interact more strongly in agreement with the major decrease in the phosphorescence emission intensity recorded (Table 2, Figures 5 and S16-S23). It must be stressed that titrations show, in general, two different tendencies: (i) a (fast) first decrease of the phosphorescence emission (between 0 and 1 equivalent of guest added) and (ii) a recovery of some of the quenched emission reaching a plateau at 2 equivalents of the corresponding guest. Considering that the phosphorescence is expected to be enhanced by the proximity of the chromophore to the gold(I) atom, due to heavy atom effect, the observed variations let us suggest that the interaction with PAHs, especially with the anthracene and pyrene, promotes the disruption of homo-aggregates at low concentration where $\pi \cdots$ gold or gold $\cdots$ gold interactions are present. At higher concentrations, these interactions are restored to some extent with the formation of hetero-aggregates. The different behaviour in the process between host $\mathbf{1}$ and anthracene may be ascribed to the phosphorescence recovery at the end of the titration where heteroaggregates are formed from the interaction of the 1:2 adducts as exemplified in Scheme S2. In particular, it may be due to the type of the resulting intermolecular contacts. That is, heteroaggregates containing gold $\cdots \pi$ or gold $\cdots$ gold interactions in the vicinity of the chromophore are expected to induce the resulting RTP of the naphthalimide. Thus, either anthracene: 1 heterodimers do not form larger heteroaggregates in the concentration range used or the resulting aggregates' geometry do not contain this type of interactions at this concentration range. 
Table 2. Maximum variations (quenching) on the emission intensity of the host $\mathbf{1}$ or $\mathbf{2}$ in the titration with PAHs.

\begin{tabular}{ccccc}
\hline Host/Guest & Anthracene & Naphthalene & Phenanthrene & Pyrene \\
\hline $\mathbf{1}$ & $85 \%$ & $<10 \%$ & $88 \%$ & $60 \%$ \\
\hline $\mathbf{2}$ & $90 \%$ & $<10 \%$ & $90 \%$ & $90 \%$ \\
\hline
\end{tabular}
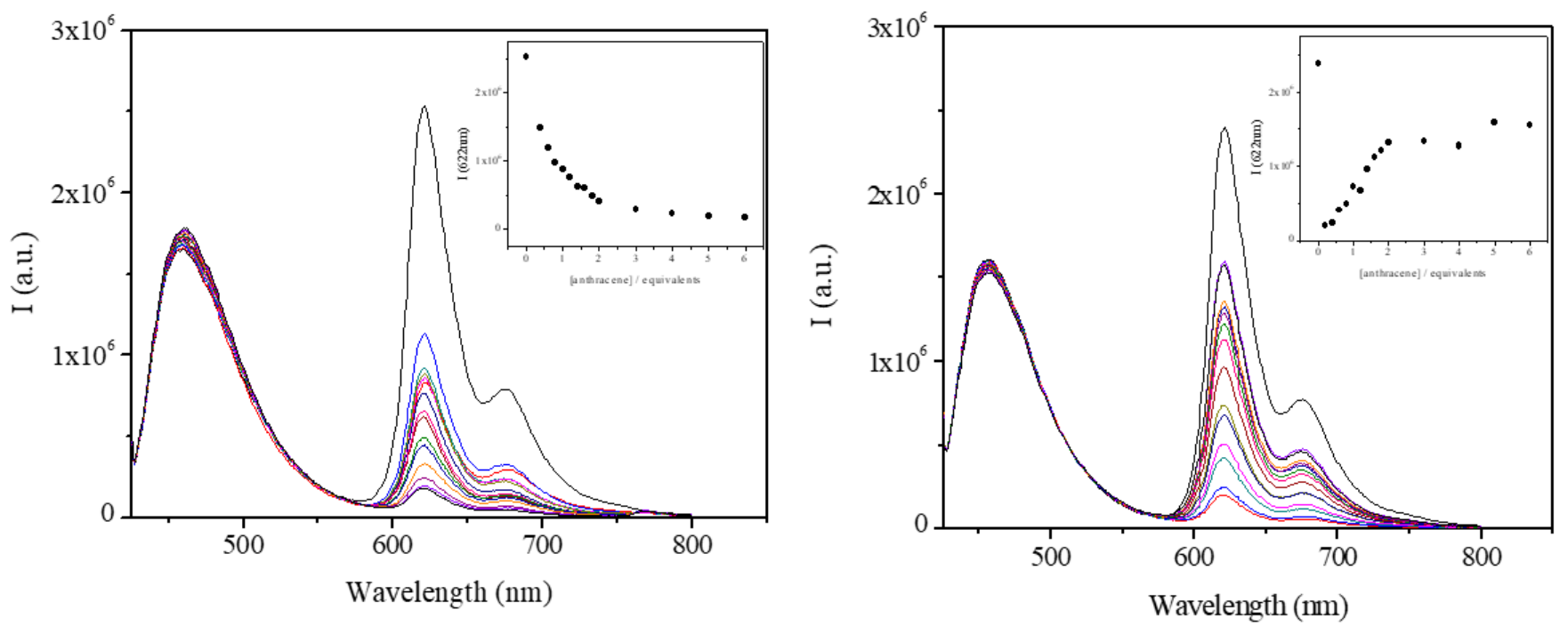

Figure 5. Emission spectra of $\mathbf{1}$ (left) and $\mathbf{2}$ (right) in the presence of different amounts of anthracene. Inset: variations of the emission maxima at $622 \mathrm{~nm}$ against [anthracene].

${ }^{1} \mathrm{H}-\mathrm{NMR}$ experiments did not give structural information of the resulting host:guest adducts since all the host solutions are strongly aggregated at the required NMR concentrations and the peaks are not affected by the addition of the guests (Figures S24-S31).

The calculated geometric and energetic features of 1:1 and 1:2 adducts between hosts 1 and $\mathbf{2}$ and naphthalene $(\mathrm{N})$, anthracene $(\mathrm{A})$, phenanthrene $(\mathrm{Ph})$, and pyrene $(\mathrm{P})$ are shown in Figures 6 and 7, respectively. In all cases the binding site is the naphthalimide that forms stacking interactions with the PAHs. The $1: 1$ complexes $1 \cdots \mathrm{Ph}, 1 \cdots \mathrm{A}$, and $1 \cdots \mathrm{P}$ exhibit similar interaction energies $(-14.6,-15.0$, and $-15.8 \mathrm{kcal} / \mathrm{mol}$, respectively), which are larger (in absolute value) than that of complex $1 \cdots \mathrm{N}(-11.7 \mathrm{kcal} / \mathrm{mol}$, respectively). A similar trend is observed in the 1:2 complexes, where $\mathrm{Ph}, \mathrm{A}$ and $\mathrm{P}$ exhibit stronger binding than $\mathrm{N}$. The 1:2 complexes are energetically more favorable than the homodimer $\mathbf{1} \cdots \mathbf{1}$ for $\mathrm{Ph}, \mathrm{A}$, and $\mathrm{P}$ supporting the disaggregation of the host molecules in the presence of these PAHs, as displayed through emission titrations. The opposite is observed for $\mathrm{N}$, in agreement with the absence of interaction detected experimentally for this PAH.

The energies gathered in Figure 6 for the 1:1 and 1:2 complexes suggest that the binding of the first molecule of PAH has little influence on the binding of the second molecule of $\mathrm{PAH}$, thus indicating a lack of cooperativity effects.

The optimized geometries of 1:1 and 1:2 complexes of compound 2 with the PAHs are displayed in Figure 7 and they are similar to those detailed above for compound 1. The largest 1:1 binding energies are expected for complexes $2 \cdots \mathrm{P}, 2 \cdots \mathrm{A}$, and $2 \cdots \mathrm{Ph}$ with the calculated energies of $-16.3,-15.0$, and $-14.6 \mathrm{kcal} / \mathrm{mol}$, respectively. Again the naphthalene complex is the weakest $(-11.9 \mathrm{kcal} / \mathrm{mol})$. A similar trend is observed in the 1:2 complexes. 

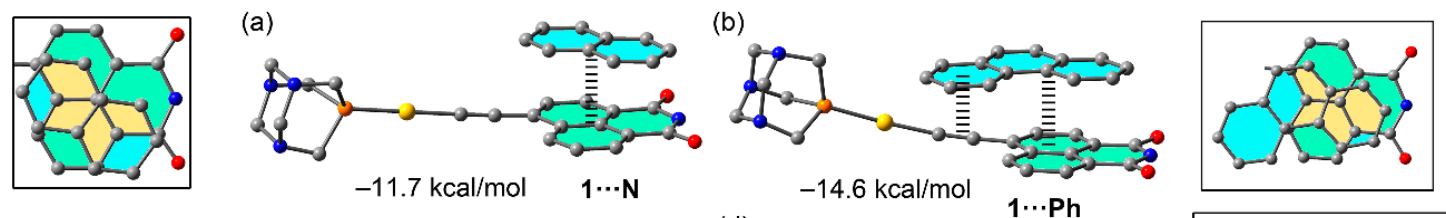

(c)
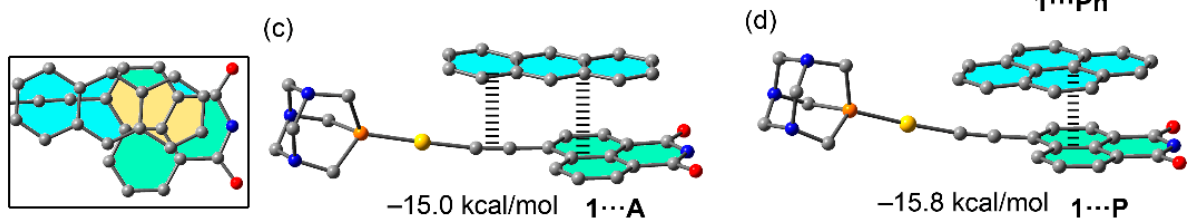

$-15.8 \mathrm{kcal} / \mathrm{mol} \quad \mathbf{1} \cdots \mathrm{P}$
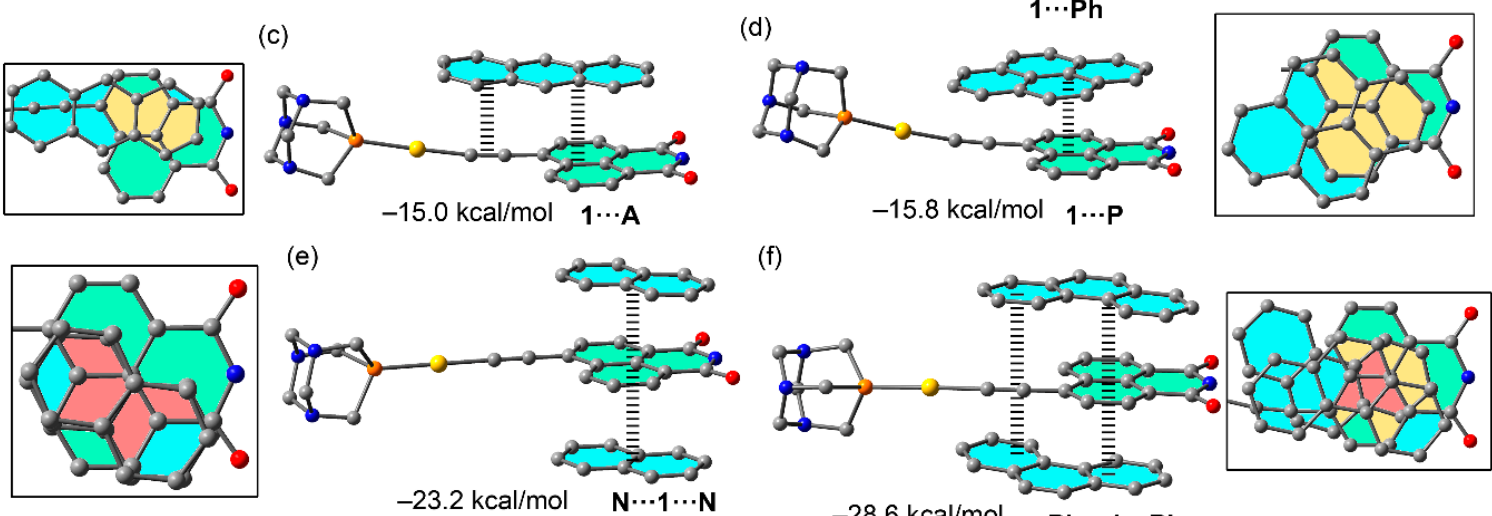

(g)

(h)
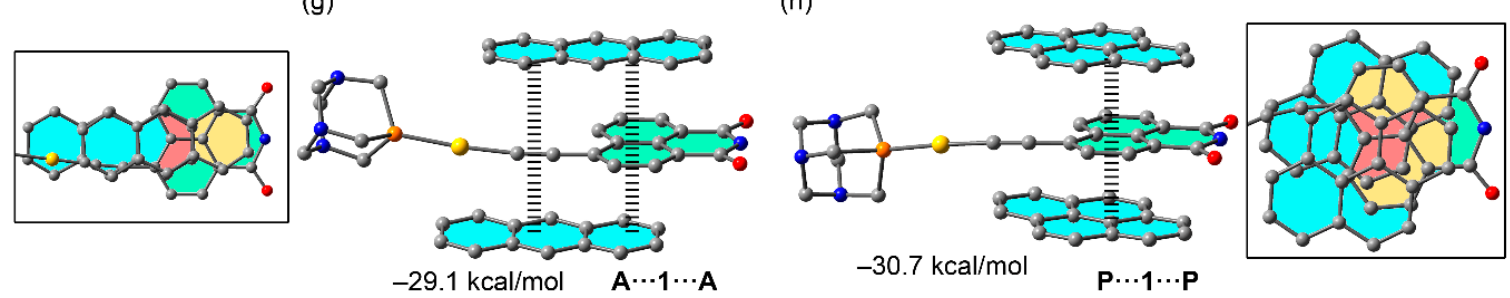

Figure 6. PB86-D3(COSMO)/def2-TZVP optimized geometries and binding energies of the dimers $1 \cdots \mathrm{N}(\mathbf{a}), 1 \cdots \mathrm{Ph}(\mathbf{b})$, $1 \cdots \mathrm{A}(\mathbf{c}) 1 \cdots \mathrm{P}(\mathbf{d})$ and trimers $\mathrm{N} \cdots 1 \cdots \mathrm{N}(\mathbf{e}), \mathrm{Ph} \cdots 1 \cdots \mathrm{Ph}(\mathbf{f}), \mathrm{A} \cdots 1 \cdots \mathrm{A}(\mathbf{g}) \mathrm{P} \cdots 1 \cdots \mathrm{P}(\mathbf{h})$.
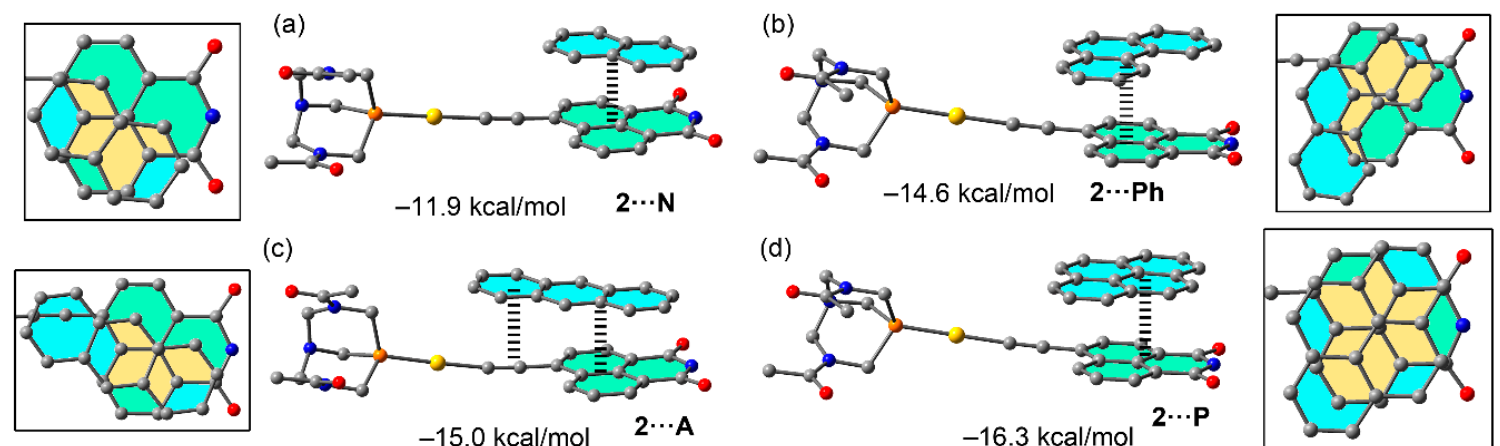

(c)
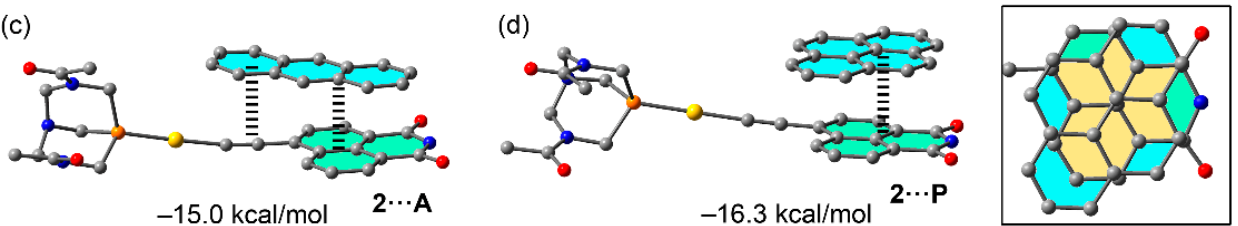

(e)
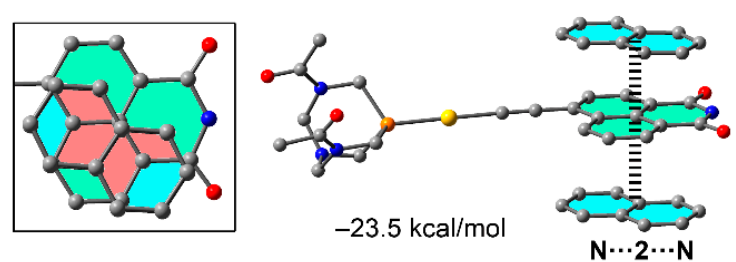

(f)

(g)
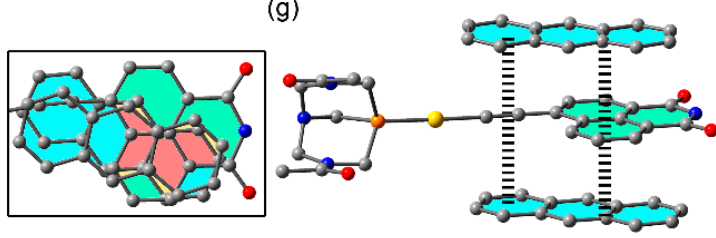

$-28.8 \mathrm{kcal} / \mathrm{mol}$

A $\cdots 2 \cdots A$
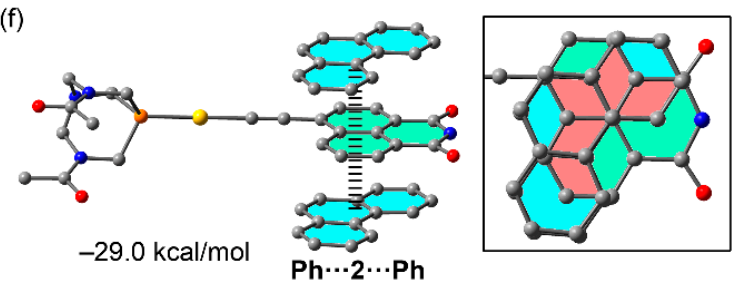

(h)
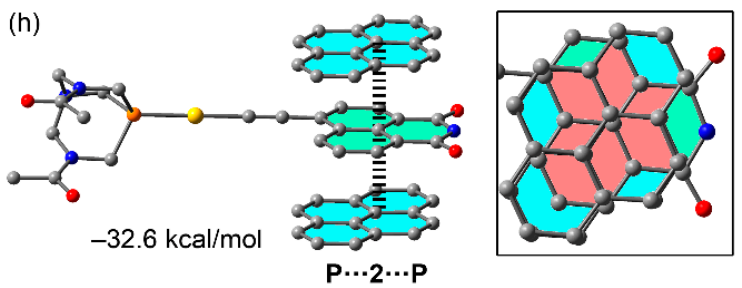

Figure 7. PB86-D3(COSMO)/def2-TZVP optimized geometries and binding energies of the dimers $2 \cdots \mathrm{N}(\mathbf{a}), 2 \cdots \mathrm{Ph}(\mathbf{b})$, $2 \cdots \mathrm{A}(\mathbf{c}) 2 \cdots \mathrm{P}(\mathbf{d})$ and trimers $\mathrm{N} \cdots 2 \cdots \mathrm{N}(\mathbf{e}), \mathrm{Ph} \cdots 2 \cdots \mathrm{Ph}(\mathbf{f}), \mathrm{A} \cdots 2 \cdots \mathrm{A}(\mathrm{g}) \mathrm{P} \cdots 2 \cdots \mathrm{P}(\mathbf{h})$. 
The reaction energies of the following hypothetical transformations $(\mathbf{H} \cdots \mathbf{H})+2 \times$ $\mathrm{PAH} \rightarrow 2 \times(\mathbf{H} \cdots \mathrm{PAH})$, where $\mathbf{H}$ stands for hosts $\mathbf{1}$ and $\mathbf{2}$ and $\mathrm{PAH}=\mathrm{N}, \mathrm{A}, \mathrm{Ph}$ and $\mathrm{P}$, have also been computed. The corresponding reaction energies for such transformations, namely $\Delta \mathrm{E}_{\mathrm{d} 1}$ (for 1) and $\Delta \mathrm{E}_{\mathrm{d} 2}$ (for 2), are gathered in Table 2. That is, assuming that the dimer is the predominant specie in solution, the $\Delta \mathrm{E}_{\mathrm{d}}$ values give hints about the feasibility to transform this strong homodimer $(\mathbf{1} \cdots \mathbf{1}$ or $2 \cdots 2)$ into two heterodimers upon the addition of one equivalent of PAH (Table 3). It can be observed that in the case of $\mathbf{1}$ the $\Delta \mathrm{E}_{1 \mathrm{~d}}$ values suggest that the three larger $\mathrm{A}, \mathrm{Ph}$ and $\mathrm{P}$ are able to form the 1:1 hetero-dimers (exothermic process). In the case of 2 , the $\Delta \mathrm{E}_{2 \mathrm{~d}}$ values are in all cases negative, thus suggesting that all PAHs should be able to form the host-guest complexes. However, the value is very small for $\mathrm{N}$ compared to the others, which is in line with the experimental findings that detect a weak binding for $\mathrm{N}$. In addition, we have also calculated the formation of the heterotrimers using similar transformations: $(\mathbf{H} \cdots \mathbf{H})+4 \times \mathrm{PAH} \rightarrow 2 \times(\mathrm{PAH} \cdots \mathbf{H} \cdots \mathrm{PAH})$. The corresponding reaction energies for such transformations, where two equivalents of PAH are added, namely, $\Delta \mathrm{E}_{\mathrm{t} 1}$ (for $\mathbf{1}$ ) and $\Delta \mathrm{E}_{\mathrm{t} 2}$ (for 2), are also summarized in Table 2. All reactions are exothermic, thus suggesting than the addition of an excess of PAH should provoke the transformation of the homodimer into the heterotrimer (PAH $\cdots \mathbf{H} \cdots \mathrm{PAH})$. Inspection of Table 3 lets us to observe a direct trend between $\Delta \mathrm{E}$ and the number of aromatic rings, with more negative $\Delta \mathrm{E}$ values as the number of rings increases ( 2 for $\mathrm{N}, 3$ for $\mathrm{Ph}$ and $\mathrm{A}$ with similar $\Delta \mathrm{E}$, and 4 for $\mathrm{P}$ ) for both the heterodimers and heterotrimers.

Table 3. Formation energies of the heterodimers $\left(\Delta \mathrm{E}_{\mathrm{d} 1}\right.$ and $\left.\Delta \mathrm{E}_{\mathrm{d} 2}\right)$ and heterotrimers $\left(\Delta \mathrm{E}_{\mathrm{t} 1}\right.$ and $\left.\Delta \mathrm{E}_{\mathrm{t} 2}\right)$ in $\mathrm{kcal} / \mathrm{mol}$ for hosts $\mathbf{1}$ and $\mathbf{2}$.

\begin{tabular}{ccccc}
\hline \multirow{2}{*}{$\mathbf{P A H}$} & \multicolumn{2}{c}{ Compound 1 } & \multicolumn{2}{c}{ Compound 2 } \\
\cline { 2 - 5 } & $\Delta \mathbf{E}_{\mathbf{d} \mathbf{1}}$ & $\Delta \mathbf{E}_{\mathbf{t} 1}$ & $\Delta \mathbf{E}_{\mathbf{d} 2}$ & $\Delta \mathbf{E}_{\mathbf{t} 2}$ \\
\hline $\mathbf{N}$ & +0.8 & -22.4 & -2.7 & -25.8 \\
\hline $\mathbf{P h}$ & -4.7 & -32.8 & -7.9 & -36.9 \\
\hline $\mathbf{A}$ & -5.8 & -34.0 & -8.8 & -36.4 \\
\hline $\mathbf{P}$ & -7.2 & -37.0 & -11.5 & -43.9 \\
\hline
\end{tabular}

\section{Conclusions}

The self-assembly of phosphane-gold(I)-naphthalimide complexes gives rise to strong aggregates in solution even at very low concentrations $\left(\sim 10^{-5} \mathrm{M}\right)$. Nevertheless, the compounds show a higher affinity to interact with long PAHs compounds, such as anthracene and pyrene. This interaction induces a disassembly of the gold(I) complexes to form very sTable 1:2 (host:guest) adducts. The smaller naphthalene PAH induces little effect on the spectroscopic properties of naphthalimide-gold(I) complexes, indicating that the established $\pi-\pi$ interactions with naphthalimide are not strong enough to promote disassembly of these gold(I) complexes.

DFT calculations suggest intermolecular contacts in a head to tail disposition of the gold(I) complexes with $\mathrm{Au} \cdots \pi$ or $\mathrm{Au} \cdots \mathrm{N}-\mathrm{H}$ interactions. The proximity of the gold(I) heavy atom to the naphthalimide chromophore must be the responsible for the observed room temperature phosphorescence emission of the hosts.

\section{Materials and Methods}

\subsection{General Procedures}

All manipulations have been performed under prepurified $\mathrm{N}_{2}$ using standard Schlenk techniques. Dry solvents were dispensed from a solvent purification system (Innovative Technologies; Newburyport, MA, USA). Commercial reagents 4-bromo-naphthalic anhydride (Merck, Darmstadt, Germany, 95\%), Ammonium hydroxide solution (A.C.S reagent, 28-30\%), ethynyltrimethylsilane (Merck, 98\%), Copper (I) iodide (Merck, 98\%), triethylamine (Merck, 99.5\%), 1,3,5-triaza-7-phosphaadamantane (Merck, 97\%), tetrabuty- 
lammonium fluoride (TBAF, $1 \mathrm{M}$ in tetrahydrofuran, Panreac), naphthalene (Koch-Light Labs, Haverhill, UK), anthracene ( $\geq 99 \%$, Merck), phenanthrene ( $\geq 99.5 \%$, Merck), and pyrene ( $\geq 99 \%$, Merck) were used as received.

\subsection{Physical Measurements}

Infrared spectra have been recorded on a FT-IR 520 Nicolet Spectrophotometer. ${ }^{1} \mathrm{H}$ $\operatorname{NMR}(\delta(\mathrm{TMS})=0.0 \mathrm{ppm})$ and ${ }^{31} \mathrm{P}\left\{{ }^{1} \mathrm{H}\right\} \mathrm{NMR}\left(\delta\left(85 \% \mathrm{H}_{3} \mathrm{PO}_{4}\right)=0.0 \mathrm{ppm}\right)$ spectra have been obtained on a Varian Mercury 400, Bruker 400, and Bruker 500. ES(+) mass spectra were recorded on a Fisons VG Quatro spectrometer. Absorption spectra have been recorded on a Varian Cary 100 Bio UV-Spectrophotometer and emission spectra on a Horiba-Jobin-Ybon SPEX Nanolog Spectrofluorimeter.

\subsection{Theoretical Methods}

The calculations of the dimers and trimers were performed at the DFT level of theory using PB86 functional [44] the def2-TZVP basis set [45] and the D3 dispersion correction e4we [46] with the help of the Turbomole 7.0 program package [47]. Solvent effects were considered using COSMO (solvent DMSO) during the optimization [48]. The MEP surfaces were computed at the PB86-D3/def2-TZVP level of theory and visualized using the Gaussview [49] and using the cubes generated by the Multiwfn software [50] and the wavefunction obtained using Turbomole 7.0 (TURBOMOLE GmbH, Karlsruhe, Germany).

\subsection{Absorption and Emission Titrations}

Absorption and emission spectra were recorded using a quartz cuvette with a path length of $10 \times 10 \mathrm{~mm}$ and a volume of $3 \mathrm{~mL}$. All solutions were prepared with dry DMSO, diluted from a more concentrated stock solution, and used on the same day they were prepared.

\subsection{Synthesis and Characterization}

Synthesis of 6-Bromo-1H-benzo[de].isoquinoline-1,3(2H)-dione (P1)

The synthesis of this compound was adapted from the previous reported in the literature [35].

4-Bromo-1,8-naphthalic anhydride ( $507 \mathrm{mg}, 1.83 \mathrm{mmol}, 1$ eq.) was suspended in EtOH $(10 \mathrm{~mL})$ and $1.50 \mathrm{~mL}$ of a $20 \% \mathrm{NH}_{3}$ solution was added. The mixture was refluxed for $3 \mathrm{~h}$, cooled down to r.t., filtrated and washed with $\mathrm{EtOH}$ giving a beige solid $(429 \mathrm{mg}, 85 \%)$. ${ }^{1} \mathrm{H}-\mathrm{NMR}\left(400 \mathrm{MHz}, \mathrm{CDCl}_{3}\right): \delta=8.65(\mathrm{~m}, J=8.4 \mathrm{~Hz}, 2 \mathrm{H}), 8.52(\mathrm{~s}, 1 \mathrm{H}), 8.42(\mathrm{~d}, J=7.9 \mathrm{~Hz}$, $1 \mathrm{H}), 8.08(\mathrm{~d}, J=7.9 \mathrm{~Hz}, 1 \mathrm{H}), 7.88(\mathrm{t}, J=7.9 \mathrm{~Hz}, 1 \mathrm{H})$. ESI-MS(+): $\mathrm{m} / z=$ calc. $275.97[\mathrm{M}+\mathrm{H}] .^{+}$, found 275.97 .

Synthesis of 6-((Trimethylsilyl)ethynyl)-1H-benzo[de].isoquinoline-1,3(2H)-dione (P2)

6-Bromo-1H-benzo[de].isoquinoline-1,3(2H)-dione ( $299 \mathrm{mg}, 1.08 \mathrm{mmol}, 1.00$ eq.) was suspended in dry THF $(8 \mathrm{~mL})$ under $\mathrm{N}_{2}$ atmosphere and TMS-acetylene $(150 \mathrm{mg}, 1.53 \mathrm{mmol}$, 1.40 eq.) in THF $(2 \mathrm{~mL})$ was added. $\mathrm{CuI}(20 \mathrm{mg}, 6 \mathrm{~mol} \%)$ and $\left[\mathrm{PdCl}_{2}\left(\mathrm{PPh}_{3}\right)_{2}\right] .(18 \mathrm{mg}$, $3 \mathrm{mmol})$ were dissolved in dry THF $(5 \mathrm{~mL})$ and $\mathrm{NEt}_{3}(6 \mathrm{~mL})$ was added, then the mixture was added to the previous one and left stirring overnight. DCM $(20 \mathrm{~mL})$ was added and the precipitate removed by filtration. The organic layer was washed with sat. $\mathrm{NH}_{4} \mathrm{Cl}$ solution $(3 \times 10 \mathrm{~mL})$, water $(2 \times 10 \mathrm{~mL})$, and brine $(10 \mathrm{~mL})$, dried over $\mathrm{MgSO}_{4}$ and concentrated in vacuum. Purification by column chromatography $\left(\mathrm{SiO}_{2}, \mathrm{DCM} /\right.$ acetone $\left.[10: 1] ., v / v\right)$ yielded P2 as yellow solid $(180 \mathrm{mg}, 57 \%) .{ }^{1} \mathrm{H}-\mathrm{NMR}\left(400 \mathrm{MHz}, \mathrm{CDCl}_{3}\right): \delta=8.69(\mathrm{~d}, J=8.4 \mathrm{~Hz}, 1 \mathrm{H})$, $8.63(\mathrm{~d}, J=7.3 \mathrm{~Hz}, 1 \mathrm{H}), 8.52(\mathrm{dd}, J=7.6,1.1 \mathrm{~Hz}, 1 \mathrm{H}), 7.91(\mathrm{~d}, J=7.6 \mathrm{~Hz}, 1 \mathrm{H}), 7.84(\mathrm{dd}, J=8.2$, $7.5 \mathrm{~Hz}, 1 \mathrm{H}), 0.37(\mathrm{~s}, 9 \mathrm{H})$.

Synthesis of 6-Ethynyl-1H-benzo[de].isoquinoline-1,3(2H)-dione (L)

6-((Trimethylsilyl)ethynyl)-1H-benzo[de].isoquinoline-1,3(2H)-dione was dissolved in THF $(10 \mathrm{~mL})$ and water $(1 \mathrm{~mL})$ was added. $1 \mathrm{M}$ TBAF solution in THF $(1.25 \mathrm{~mL}, 1.25 \mathrm{mmol}$, 2.22 eq.) was added at r.t. and the orange mixture was stirred for $3 \mathrm{~h}$. Water $(5 \mathrm{~mL})$ was added and a precipitate formed. The mixture was extracted with DCM $(4 \times 10 \mathrm{~mL})$ and 
washed with water $(2 \times 10 \mathrm{~mL})$ and brine $(10 \mathrm{~mL})$, then dried over $\mathrm{MgSO}_{4}$. After removing the solvent in vacuum, the solid was washed with hexane and $\mathrm{Et}_{2} \mathrm{O}$, yielding $\mathrm{L}$ as pale ochre solid (64 mg, 51\%). ${ }^{1} \mathrm{H}-\mathrm{NMR}\left(400 \mathrm{MHz}, \mathrm{CDCl}_{3}\right): \delta=8.73(\mathrm{dd}, J=8.4,1.2 \mathrm{~Hz}, 1 \mathrm{H})$, $8.64(\mathrm{dd}, J=7.6,1.2 \mathrm{~Hz}, 1 \mathrm{H}), 8.53(\mathrm{~d}, J=7.6 \mathrm{~Hz}, 1 \mathrm{H}), 8.41$ (bs, $1 \mathrm{H}), 7.97(\mathrm{~d}, J=7.6 \mathrm{~Hz}, 1 \mathrm{H})$,

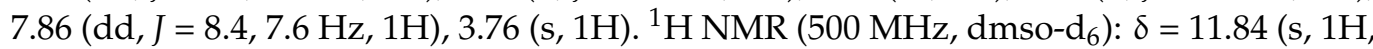
$\mathrm{NH}), 8.64(\mathrm{dd}, J=8.4,1.2 \mathrm{~Hz}, 1 \mathrm{H}), 8.51(\mathrm{dd}, J=7.6,1.2 \mathrm{~Hz}, 1 \mathrm{H}), 8.40(\mathrm{~d}, J=7.6 \mathrm{~Hz}, 1 \mathrm{H}), 8.05$ $(\mathrm{d}, J=7.6 \mathrm{~Hz}, 1 \mathrm{H}), 7.98(\mathrm{dd}, J=8.4,7.6 \mathrm{~Hz}, 1 \mathrm{H}), 5.09(\mathrm{~s}, 1 \mathrm{H}) .{ }^{13} \mathrm{C}-\mathrm{NMR}\left(125 \mathrm{MHz}, \mathrm{dmso}_{6}\right)$ : $\delta=164.1(\mathrm{CO}), 163.8(\mathrm{CO}), 131.8(\mathrm{CH}), 131.7(\mathrm{CH}), 131.6,130.7,129.4(\mathrm{CH}), 128.7,128.5(\mathrm{CH})$, 125.7, 123.2, 123.0, $90.3(\mathrm{CCH}), 80.3(\mathrm{CCH})$. Melting point: $296-298^{\circ} \mathrm{C}$.

Synthesis of $[\mathrm{Au}(\mathrm{L})(\mathrm{PTA})] .(\mathbf{1})$

L (30 mg, $0.14 \mathrm{mmol}, 1.00$ eq.) and $\mathrm{KOH}$ (40 mg, $0.68 \mathrm{mmol}, 5.00$ eq.) were suspended in dry $\mathrm{MeOH}(5 \mathrm{~mL})$ under $\mathrm{N}_{2}$ atmosphere and stirred for $30 \mathrm{~min}$. [AuCl(PTA)]. (53 mg, $0.14 \mathrm{mmol}, 1.00$ eq.) was suspended in dry DCM $(5 \mathrm{~mL})$ and added to the other solution leading to the formation of a yellow precipitate. The mixture was stirred overnight, then filtrated through a glass funnel, washed with acetonitrile $(10 \mathrm{~mL})$ and $\mathrm{Et}_{2} \mathrm{O}(10 \mathrm{~mL})$ and dried in vacuum. [Au(L)(PTA)]. (1) was obtained as yellow solid (55 mg, 70\%). ${ }^{1} \mathrm{H}-\mathrm{NMR}$ $\left(400 \mathrm{MHz}, \mathrm{DMSO}-d_{6}\right): \delta=8.57(\mathrm{~d}, J=8.4 \mathrm{~Hz}, 1 \mathrm{H}), 8.33(\mathrm{~d}, J=7.2 \mathrm{~Hz}, 1 \mathrm{H}), 8.20(\mathrm{~d}, J=7.6 \mathrm{~Hz}$, $1 \mathrm{H}), 7.81(\mathrm{dd}, J=8.4 \mathrm{~Hz}, J=7.2 \mathrm{~Hz}, 1 \mathrm{H}), 7.68(\mathrm{~d}, J=7.6 \mathrm{~Hz}, 1 \mathrm{H}), 4.52-4.32(\mathrm{~m}, 12 \mathrm{H}) .{ }^{31} \mathrm{P}$ NMR (162 MHz, DMSO- $\left.d_{6}\right): \delta=-49.5 .0$ (s), -20 (s). ESI-MS(+): $m / z=$ calc. 575.0866 $[\mathrm{M}+\mathrm{H}] .^{+}$, found 575.0922 .

Synthesis of $[\mathrm{Au}(\mathrm{L})(\mathrm{DAPTA})]$. (2)

L (23 mg, $0.10 \mathrm{mmol}, 1.00$ eq.) and $\mathrm{KOH}$ (19 mg, $0.634 \mathrm{mmol}, 3.00$ eq.) were suspended in dry $\mathrm{MeOH}(8 \mathrm{~mL})$ under $\mathrm{N}_{2}$ atmosphere and stirred for $30 \mathrm{~min}$. [AuCl(DAPTA)]. (48 mg, $0.10 \mathrm{mmol}, 1.00$ eq.) was suspended in dry DCM $(5 \mathrm{~mL})$ and added to the other solution leading to the formation of a yellow precipitate. The mixture was stirred overnight, then filtrated through a glass funnel, washed with acetonitrile $(10 \mathrm{~mL})$ and $\mathrm{Et}_{2} \mathrm{O}(10 \mathrm{~mL})$ and dried in vacuum. [Au(L)(DAPTA)]. (2) was obtained as yellow solid $(46 \mathrm{mg}, 68 \%) .{ }^{1} \mathrm{H}-$ NMR $\left(400 \mathrm{MHz}\right.$, DMSO- $\left.d_{6}\right) \delta=8.63(\mathrm{~d}, J=8.0 \mathrm{~Hz}, 1 \mathrm{H}), 8.33(\mathrm{~d}, J=7.2 \mathrm{~Hz}, 1 \mathrm{H}), 8.19$ $(\mathrm{d}, J=7.2 \mathrm{~Hz}, 1 \mathrm{H}), 7.80(\mathrm{dd}, J=8.0 \mathrm{~Hz}, J=7.2 \mathrm{~Hz}, 1 \mathrm{H}), 7.64(\mathrm{~d}, J=7.2 \mathrm{~Hz}, 1 \mathrm{H}), 5.50(\mathrm{~d}$, $J=13.6 \mathrm{~Hz}, 1 \mathrm{H}), 5.40(\mathrm{~m}, 1 \mathrm{H}), 4.90(\mathrm{~m}, 1 \mathrm{H}), 4.61(\mathrm{~d}, J=14 \mathrm{~Hz}, 1 \mathrm{H}), 4.30(\mathrm{~d}, J=15.6 \mathrm{~Hz}, 1 \mathrm{H})$, $4.09(\mathrm{~d}, J=14 \mathrm{~Hz}, 1 \mathrm{H}), 4.03(\mathrm{~s}, 2 \mathrm{H}), 3.77(\mathrm{~d}, J=16 \mathrm{~Hz}, 1 \mathrm{H}) .{ }^{31} \mathrm{P}-\mathrm{NMR}\left(162 \mathrm{MHz}, \mathrm{DMSO}-d_{6}\right)$ $\delta=-26.9$ (s). ESI-MS(+): $m / z=$ calc. $647.1078[\mathrm{M}+\mathrm{H}] .{ }^{+}$, found 647.1134 .

Supplementary Materials: The following are available, Figure S1: ${ }^{1} \mathrm{H}$ NMR spectrum of $\mathrm{P} 1$ in $\mathrm{CDCl}_{3}$, Figure S2: ${ }^{1} \mathrm{H}$ NMR spectrum of $\mathrm{P} 2$ in $\mathrm{CDCl}_{3}$, Figure S3: ${ }^{1} \mathrm{H}$ NMR spectra of $\mathrm{L}$ in $\mathrm{CDCl}_{3}$ and DMSO$d_{6}$,Figure S4: ${ }^{13}$ C-NMR spectrum of $\mathbf{L}$ in DMSO- $d_{6}$, Figure S5: HSQC NMR spectrum of L in DMSO- $d_{6}$, Figure S6: ${ }^{1} \mathrm{H}-\mathrm{NMR}$ spectrum of 1 in DMSO- $d_{6}$, Figure S7: ${ }^{31} \mathrm{P}\left\{{ }^{1} \mathrm{H}\right\}$ NMR spectrum of $\mathbf{1}$ in DMSO- $d_{6}$, Figure S8: ${ }^{1} \mathrm{H}-\mathrm{NMR}$ spectrum of 2 in DMSO- $d_{6}$, Figure S9: ${ }^{31} \mathrm{P}\left\{{ }^{1} \mathrm{H}\right\}$ NMR spectrum of 2 in DMSO$d_{6}$, Figure S10: Absorption and emission spectra of $\mathbf{1}$ and $\mathbf{2}$ in air-equilibrated and $\mathrm{N}_{2}$-saturated solutions, Figure S11: Absorption and Emission spectra of $\mathbf{L}$ in dichloromethane at $2 \times 10^{-4} \mathrm{M}$ concentration $\left(\lambda_{\text {exc }}=330 \mathrm{~nm}\right)$, Figure S12: ${ }^{1} \mathrm{H}-\mathrm{NMR}$ spectrum of freshly dissolved solution of 2 in DMSO- $d_{6}$, Figure S13: Emission spectra 1 at different concentrations in DMSO $\left(\lambda_{\text {exc }}=370 \mathrm{~nm}\right)$, Figure S14: Emission spectra of 2 at different concentrations in DMSO $\left(\lambda_{\text {exc }}=370 \mathrm{~nm}\right)$. Inset: Plot of the intensity of the emission at $435 \mathrm{~nm}$ against concentration, Figure S15: Optical microscopy images of $\mathbf{1}$ (A) and $\mathbf{2}$ (B) in DMSO at c.a.c., Figure S16: Absorption spectra of $\mathbf{1}$ in the presence of different amounts of anthracene, Figure S17: Absorption and Emission spectra of $\mathbf{1}$ in the presence of different amounts of naphthalene. Inset: variations of the emission maxima at $622 \mathrm{~nm}$ against [naphthalene], Figure S18: Absorption and Emission spectra of $\mathbf{1}$ in the presence of different amounts of phenanthrene. Inset: variations of the emission maxima at $622 \mathrm{~nm}$ against [phenanthrene], Figure S19: Absorption and Emission spectra of $\mathbf{1}$ in the presence of different amounts of pyrene. Inset: variations of the emission maxima at $622 \mathrm{~nm}$ against [pyrene], Figure S20: Absorption spectra of $\mathbf{2}$ in the presence of different amounts of anthracene, Figure S21: Absorption and Emission spectra of $\mathbf{2}$ in the presence of different amounts of naphthalene. Inset: variations of the emission maxima at $622 \mathrm{~nm}$ against [naphthalene], Figure S22: Absorption and Emission spectra of 2 in the presence of different amounts of phenanthrene. Inset: variations of the emission maxima at $622 \mathrm{~nm}$ against 
[phenanthrene], Figure S23: Emission spectra of 2 in the presence of different amounts of pyrene. Inset: variations of the emission maxima at $622 \mathrm{~nm}$ against [pyrene], Figure S24: ${ }^{1} \mathrm{H}$ NMR spectra in DMSO- $d_{6}$ of 1, anthracene and 1:1 adduct 1:anthracene, Figure S25: ${ }^{1} \mathrm{H}$ NMR spectra in DMSO- $d_{6}$ of 1, naphthalene and 1:1 adduct 1: naphthalene, Figure S26: ${ }^{1} \mathrm{H}$ NMR spectra in DMSO- $d_{6}$ of 1, pyrene and 1:1 adduct 1: pyrene, Figure S27: ${ }^{1} \mathrm{H}$ NMR spectra in DMSO- $d_{6}$ of $\mathbf{1}$, phenanthrene and 1:1 adduct 1: phenanthrene, Figure S28: ${ }^{1} \mathrm{H}$ NMR spectra in DMSO- $d_{6}$ of 2, anthracene and 1:1 adduct 2:anthracene, Figure S29: ${ }^{1} \mathrm{H}-\mathrm{NMR}$ spectra in DMSO- $d_{6}$ of 2, naphthalene and 1:1 adduct 2: naphthalene, Figure S30: ${ }^{1} \mathrm{H}$ NMR spectra in DMSO- $d_{6}$ of 2, pyrene and 1:1 adduct 2: pyrene, Figure S31: ${ }^{1} \mathrm{H}$ NMR spectra in DMSO- $d_{6}$ of 2 , phenantrene and 1:1 adduct 2: phenantrene, Scheme S1: Experimental procedure for the synthesis of $\mathbf{L}$, Scheme S2: Schematic representation of the possible rationalization of the different steps of the host:guest interaction and resulting aggregates.

Author Contributions: M.R.; R.N.C.; A.J.M.; I.A.: synthesis and characterization of the complexes; photophysical characterization and absorption and emission titrations. R.M.G. theoretical calculations. A.F.: supervision and report of the theoretical calculations results. J.C.L. supervision and support on the photophysical data. L.R., global supervision of all the work and redaction of the manuscript. All authors have read and agreed to the published version of the manuscript.

Funding: The authors are grateful to the Spanish Ministerio de Ciencia, Innovación y Universidades (AEI/FEDER, UE Projects CTQ2016-76120-P and PID2019-104121GB-I00). This work was supported by the Associate Laboratory for Green Chemistry-LAQV which is financed by national funds from FCT/MCTES (UIDB/50006/2020 and UIDP/50006/2020). R.C. and M.R. are also indebted to Erasmus Exchange Program. Authors would also like to acknowledge COST Actions CA1740-Nano4clinics and CA18202-NECTAR, International Research Network Hetero-elements and Coordination Chemistry: from Concepts to Applications (HC3A) and Spanish network Materiales Supramoleculares Funcionales (RED2018-102331-T).

Institutional Review Board Statement: Not applicable.

Informed Consent Statement: Not applicable.

Data Availability Statement: The data presented in this study are available on request from the corresponding author.

Conflicts of Interest: The authors declare not conflicts of interest.

Sample Availability: Samples of the compounds L, $\mathbf{1}$ and $\mathbf{2}$ are available from the authors.

\section{References}

1. Gopikrishna, P.; Meher, N.; Iyer, P.K. Functional 1,8-Naphthalimide AIE/AIEEgens: Recent advances and prospects. ACS. Appl. Mater. Interfaces 2018, 10, 12081-12111. [CrossRef]

2. Mateus, D.B.G.; da Silva Souza, S.; de Bacchi Silva, R.J.; de Lima Batista, A.P.; Salviato Cicolani, R.; Murie, V.E.; Nishimura, R.H.; Clososki, G.C.; de Oliveira Filho, A.G.S.; Demets, G.J.-F.; et al. Assessment of the electronic structure of a triruthenium acetate-pyridylnaphthalimide cluster. J. Photochem. Photobiol. A. Chem. 2020, 391, 112361. [CrossRef]

3. Sonalin, S.; Pandikassala, A.; Dheepika, R.; Imran, P.M.; Nagarajan, S. Molecular aggregation stimulated tunable emission behaviour of functionalized 1,8-Naphthalimides. J. Lumin. 2019, 215, 116699. [CrossRef]

4. Ott, I.; Qian, X.; Xu, Y.; Vlecken, D.H.W.; Marques, I.J.; Kubutat, D.; Will, J.; Sheldrick, W.S.; Jesse, P.; Prokop, A.; et al. A Gold(I) phosphine complex containing a naphthalimide ligand functions as a TrxR inhibiting antiproliferative agent and angiogenesis inhibitor. J. Med. Chem. 2009, 52, 763-770. [CrossRef] [PubMed]

5. Banerjee, S.; Kitchen, J.A.; Gunnlaugsson, T.; Kelly, J.M. The effect of the 4-Amino functionality on the photophysical and DNA binding properties of alkyl-pyridinium derived 1,8-Naphthalimides. Org. Biomol. Chem. 2013, 11, 5642. [CrossRef]

6. Meher, N.; Iyer, P.K. Pendant chain engineering to fine-tune the nanomorphologies and solid state luminescence of naphthalimide AIEEgens: Application to phenolic nitro-explosive detection in water. Nanoscale 2017, 9, 7674-7685. [CrossRef]

7. Noirbent, G.; Dumur, F. Recent Advances on naphthalic anhydrides and 1,8-Naphthalimide-based photoinitiators of polymerization. Eur. Polym. J. 2020, 132, 109702. [CrossRef]

8. Wang, Y.-F.; Lu, H.-Y.; Chen, C.; Li, M.; Chen, C.-F. 1,8-Naphthalimide-based circularly polarized TADF enantiomers as the emitters for efficient orange-red OLEDs. Org. Electron. 2019, 70, 71-77. [CrossRef]

9. Felip-León, C.; Galindo, F.; Miravet, J.F. Insights into the aggregation-induced emission of 1,8-Naphthalimide-based supramolecular hydrogels. Nanoscale 2018, 10, 17060-17069. [CrossRef]

10. Srivastava, A.K.; Singh, A.; Mishra, L. Tuning of aggregation enhanced emission and solid state emission from 1,8-naphthalimide derivatives: Nanoaggregates, spectra, and DFT calculations. J. Phys. Chem. A 2016, 120, 4490-4504. [CrossRef] 
11. Yin, Y.; Chen, Z.; Fan, C.; Liu, G.; Pu, S. 1,8-Naphthalimide-based highly emissive luminophors with various mechanofluorochromism and aggregation-induced characteristics. ACS. Omega. 2019, 4, 14324-14332. [CrossRef]

12. Xu, L.; Zou, L.; Chen, H.; Ma, X. Room-temperature phosphorescence of cucurbit[7].uril recognized naphthalimide derivative. Dyes. Pigment. 2017, 142, 300-305. [CrossRef]

13. Ventura, B.; Bertocco, A.; Braga, D.; Catalano, L.; D'Agostino, S.; Grepioni, F.; Taddei, P. Luminescence properties of 1,8naphthalimide derivatives in solution, in their crystals, and in co-crystals: Toward room-temperature phosphorescence from organic materials. J. Phys. Chem. C. 2014, 118, 18646-18658. [CrossRef]

14. Chen, X.; Xu, C.; Wang, T.; Zhou, C.; Du, J.; Wang, Z.; Xu, H.; Xie, T.; Bi, G.; Jiang, J.; et al. Versatile room-temperaturephosphorescent materials prepared from n-substituted naphthalimides: Emission enhancement and chemical conjugation. Angew. Chemie. Int. Ed. 2016, 55, 9872-9876. [CrossRef] [PubMed]

15. Guo, H.; Muro-Small, M.L.; Ji, S.; Zhao, J.; Castellano, F.N. Naphthalimide phosphorescence finally exposed in a platinum(II) diimine complex. Inorg. Chem. 2010, 49, 6802-6804. [CrossRef] [PubMed]

16. Zhong, F.; Zhao, J. An N^N Platinum(II) Bis(Acetylide) complex with naphthalimide and pyrene ligands: Synthesis, photophysical properties, and application in triplet-triplet annihilation upconversion. Eur. J. Inorg. Chem. 2017, 2017, 5196-5204. [CrossRef]

17. Pomestchenko, I.E.; Luman, C.R.; Hissler, M.; Ziessel, R.; Castellano, F.N. Room temperature phosphorescence from a platinum(II) diimine bis(pyrenylacetylide) complex. Inorg. Chem. 2003, 42, 1394-1396. [CrossRef] [PubMed]

18. Aquino, A.; Caparrós, F.J.; Aullón, G.; Ward, J.S.; Rissanen, K.; Jung, Y.; Choi, H.; Lima, J.C.; Rodríguez, L. Effect of Gold(I) on the room-temperature phosphorescence of ethynylphenanthrene. Chem. A. Eur. J. 2021, 27, 1810-1820. [CrossRef]

19. de Aquino, A.; Caparrós, F.J.; Truong, K.; Rissanen, K.; Ferrer, M.; Jung, Y.; Choi, H.; Lima, J.C.; Rodríguez, L. Gold(I)-doped films: New routes for efficient room temperature phosphorescent materials. Dalton Trans. 2021, 50, 3806-3815. [CrossRef]

20. Moro, A.J.; Avó, J.; Malfois, M.; Zaccaria, F.; Fonseca Guerra, C.; Caparrós, F.J.; Rodríguez, L.; Lima, J.C. Aggregation induced emission of a new naphthyridine-ethynyl-Gold(I) complex as a potential tool for sensing guanosine nucleotides in aqueous media. Dalton Trans. 2020, 49, 171-178. [CrossRef]

21. Pinto, A.; Spigolon, G.; Gavara, R.; Zonta, C.; Licini, G.; Rodríguez, L. Tripodal Gold(I) polypyridyl complexes and their Cu ${ }^{+}$and $\mathrm{Zn}^{2+}$ heterometallic derivatives. Effects on luminescence. Dalton Trans. 2020, 49, 14613-14625. [CrossRef] [PubMed]

22. Langdon-Jones, E.E.; Lloyd, D.; Hayes, A.J.; Wainwright, S.D.; Mottram, H.J.; Coles, S.J.; Horton, P.N.; Pope, S.J.A. AlkynylNaphthalimide fluorophores: Gold coordination chemistry and cellular imaging applications. Inorg. Chem. 2015, 54, 6606-6615. [CrossRef] [PubMed]

23. Ostrowski, A.D.; Ford, P.C. Metal complexes as photochemical nitric oxide precursors: Potential applications in the treatment of tumors. Dalton Trans. 2009, 48, 10660. [CrossRef] [PubMed]

24. Groves, L.M.; Williams, C.F.; Hayes, A.J.; Ward, B.D.; Isaacs, M.D.; Symonds, N.O.; Lloyd, D.; Horton, P.N.; Coles, S.J.; Pope, S.J.A. Fluorescent functionalised naphthalimides and their $\mathrm{Au}(\mathrm{I})-\mathrm{NHC}$ complexes for potential use in cellular bioimaging. Dalton Trans. 2019, 48, 1599-1612. [CrossRef]

25. Meyer, A.; Oehninger, L.; Geldmacher, Y.; Alborzinia, H.; Wölfl, S.; Sheldrick, W.S.; Ott, I. Gold(I) N-heterocyclic carbene complexes with naphthalimide ligands as combined thioredoxin reductase inhibitors and DNA intercalators. Chem. Med. Chem. 2014, 9, 1794-1800. [CrossRef]

26. Streciwilk, W.; Terenzi, A.; Lo Nardo, F.; Prochnow, P.; Bandow, J.E.; Keppler, B.K.; Ott, I. Synthesis and Biological evaluation of organometallic complexes bearing bis-1,8-Naphthalimide ligands. Eur. J. Inorg. Chem. 2018, 2018, 3104-3112. [CrossRef]

27. Liu, L.; Qu, H.; Li, X.; Zhou, X.; Zhang, J.; Sun, Y.; Cheng, J.; Zhou, L. Novel naphthalimide derived fluorescent probe based on aggregation-induced emission for turn-on detection of hydrogen sulfide. Tetrahedron 2021, 81, 131923. [CrossRef]

28. Zhou, S.; Rong, Y.; Wang, H.; Liu, X.; Wei, L.; Song, X. A naphthalimide-indole fused chromophore-based fluorescent probe for instantaneous detection of thiophenol with a red emission and a large stokes shift. Sensors Actuators B Chem. 2018, 276, 136-141. [CrossRef]

29. Oshchepkov, A.S.; Oshchepkov, M.S.; Oshchepkova, M.V.; Al-Hamry, A.; Kanoun, O.; Kataev, E.A. Naphthalimide-based fluorescent polymers for molecular detection. Adv. Opt. Mater. 2021, 9, 2001913. [CrossRef]

30. Duke, R.M.; Veale, E.B.; Pfeffer, F.M.; Kruger, P.E.; Gunnlaugsson, T. Colorimetric and fluorescent anion sensors: An overview of recent developments in the use of 1,8-Naphthalimide-Based chemosensors. Chem. Soc. Rev. 2010, 39, 3936. [CrossRef]

31. Dong, H.-Q.; Wei, T.-B.; Ma, X.-Q.; Yang, Q.-Y.; Zhang, Y.-F.; Sun, Y.-J.; Shi, B.-B.; Yao, H.; Zhang, Y.-M.; Lin, Q. 1,8-Naphthalimidebased fluorescent chemosensors: Recent advances and perspectives. J. Mater. Chem. C 2020, 8, 13501-13529. [CrossRef]

32. Moro, A.J.; Santos, M.; Outis, M.; Mateus, P.; Pereira, P.M. Selective coordination of $\mathrm{Cu}^{2+}$ and subsequent anion detection based on a naphthalimide-triazine-(DPA) 2 chemosensor. Biosensors 2020, 10, 129. [CrossRef] [PubMed]

33. Tropp, J.; Ihde, M.H.; Williams, A.K.; White, N.J.; Eedugurala, N.; Bell, N.C.; Azoulay, J.D.; Bonizzoni, M. A sensor array for the discrimination of polycyclic aromatic hydrocarbons using conjugated polymers and the inner filter effect. Chem. Sci. 2019, 10, 10247-10255. [CrossRef] [PubMed]

34. Felemban, S.; Vazquez, P.; Moore, E. Future trends for in situ monitoring of polycyclic aromatic hydrocarbons in water sources: The role of immunosensing techniques. Biosensors 2019, 9, 142. [CrossRef]

35. Verma, M.; Luxami, V.; Paul, K. Synthesis, in vitro evaluation and DNA interaction studies of N-Allyl naphthalimide analogues as anticancer agents. RSC. Adv. 2015, 5, 41803-41813. [CrossRef]

36. Pujadas, M.; Rodríguez, L. Luminescent phosphine Gold(I) alkynyl complexes. Coord. Chem. Rev. 2020, 408, 213179. [CrossRef] 
37. Lima, J.C.; Rodríguez, L. Applications of Gold(i) alkynyl systems: A growing field to explore. Chem. Soc. Rev. 2011, 40, 5442. [CrossRef]

38. Kediya, S.; Manhas, A.; Lone, M.Y.; Jha, P.C. A theoretical study describing the sensing mechanism of the novel triarylborane substituted naphthalimide molecule. J. Mol. Struct. 2021, 1228, 129443. [CrossRef]

39. Zhong, F.; Zhao, J.; Hayvali, M.; Elmali, A.; Karatay, A. Effect of molecular conformation restriction on the photophysical properties of $\mathrm{N}^{\wedge} \mathrm{N}$ Platinum(II) Bis(Ethynylnaphthalimide) complexes showing close-lying 3 MLCT and 3 LE excited states. Inorg. Chem. 2019, 58, 1850-1861. [CrossRef]

40. Jena, S.; Dhanalakshmi, P.; Bano, G.; Thilagar, P. Delayed fluorescence, room temperature phosphorescence, and mechanofluorochromic naphthalimides: Differential imaging of normoxia and hypoxia live cancer cells. J. Phys. Chem. B 2020, 124, 5393-5406. [CrossRef]

41. Yarnell, J.E.; Wells, K.A.; Palmer, J.R.; Breaux, J.M.; Castellano, F.N. Excited-State Triplet equilibria in a series of Re(I)naphthalimide bichromophores. J. Phys. Chem. B 2019, 123, 7611-7627. [CrossRef] [PubMed]

42. Aguiló, E.; Moro, A.J.; Outis, M.; Pina, J.; Sarmento, D.; Seixas de Melo, J.S.; Rodríguez, L.; Lima, J.C. Deactivation routes in Gold(I) polypyridyl complexes: Internal conversion vs fast intersystem crossing. Inorg. Chem. 2018, 57, 13423-13430. [CrossRef] [PubMed]

43. Aguiló, E.; Moro, A.J.; Gavara, R.; Alfonso, I.; Pérez, Y.; Zaccaria, F.; Guerra, C.F.; Malfois, M.; Baucells, C.; Ferrer, M.; et al. Reversible self-assembly of water-soluble Gold(I) complexes. Inorg. Chem. 2018, 57, 1017-1028. [CrossRef] [PubMed]

44. Perdew, J.P. Density-functional approximation for the correlation energy of the inhomogeneous electron gas. Phys. Rev. B 1986, 33, 8822-8824. [CrossRef] [PubMed]

45. Weigend, F. Accurate coulomb-fitting basis sets for H to Rn. Phys. Chem. Chem. Phys. 2006, 8, 1057. [CrossRef] [PubMed]

46. Grimme, S.; Antony, J.; Ehrlich, S.; Krieg, H. A Consistent and accurate Ab initio parametrization of density functional dispersion correction (DFT-D) for the 94 elements H-Pu. J. Chem. Phys. 2010, 132, 154104. [CrossRef]

47. Ahlrichs, R.; Bär, M.; Häser, M.; Horn, H.; Kölmel, C. Electronic structure calculations on workstation computers: The program system turbomole. Chem. Phys. Lett. 1989, 162, 165-169. [CrossRef]

48. Klamt, A.; Schüürmann, G. COSMO: A new approach to dielectric screening in solvents with explicit expressions for the screening energy and its gradient. J. Chem. Soc. Perkin. Trans. 1993, 5, 799-805. [CrossRef]

49. Dennington, R.; Keith, T.A.; Millam, J.M. GaussView, Version 6; Semichem Inc.: Shawnee Mission, KS, USA, 2016.

50. Lu, T.; Chen, F. Multiwfn: A multifunctional wavefunction analyzer. J. Comput. Chem. 2012, 33, 580-592. [CrossRef] [PubMed] 